Whereas studies of patients with heart failure have correlated TNF levels with the severity of heart failure ${ }^{2}$ and prediction of mortality, ${ }^{3-5}$ the exact origin of elevated circulating TNF levels during myocardial ischemia and heart failure is still unclear. Interestingly, TNF has been suggested to have a protective negative inotropic action on the failing heart, contradicting the previous paradigm of TNF being harmful. ${ }^{6}$ TNF has also been implicated in the production of heat shock proteins, enabling cells to survive stressful conditions such as ischemia. ${ }^{7}$ Placebocontrolled studies have shown that targeted therapy antagonising TNF in patients with moderate-to-severe heart failure has resulted in increased mortality and hospitalisations and the potential induction of a new onset of heart failure or exacerbation of existing disease. It is unclear whether TNF antagonists are safe in heart transplant recipients. Compared with heart transplant recipients without rejection, plasma TNF$\alpha$ levels were significantly higher in patients with moderate to severe graft rejection. ${ }^{8}$

In the current case study, case 1 underwent heart transplant surgery in 2002 and subsequently a partial colectomy, and was treated with eight weeks of adjuvant chemotherapy for stage $2 \mathrm{~A}$ colon cancer, initiating infliximab in 2005. The patient has been doing well with infliximab, with no noticeable worsening of the skin disease towards the end of the six-week infusion schedule. Case 2 suffered from dilated and congestive cardiomyopathy status after heart transplantation in May 2002. The patient's rheumatoid arthritis remained active while on methotrexate and prednisone therapy. The patient began infliximab in 2006, with a good response and complete cessation of narcotic medications; however, treatment was discontinued after four months as the patient developed bed sores. Four years after transplant surgery, we observed no complications, from a cardiac standpoint, associated with infliximab treatment. This is, to our knowledge, the first case series reporting the use of TNF antagonists in heart transplant recipients.

\section{Authors' affiliations \\ S Metyas, D La, D G Arkfeld, USC, Keck School of Medicine, Los Angeles, California, USA}

Correspondence to: Professor D G Arkfeld, University of Southern California, Keck School of Medicine, Department of Medicine -

Rheumatology, 2011 Zonal Avenue, HMR 711, Los Angeles, CA 90033, USA; arkfeld@usc.edu

Accepted 21 May 2007

\section{REFERENCES}

1 Anker SD, Coats AJS. How to RECOVER from RENAISSANCE? The significance of the results of RECOVER, RENAISSANCE, RENEWAL and ATTACH. Int J Cardiol 2002;86:123-30.

2 Torre-Amione G, Kapadia S, Benedict C, et al. Proinflammatory cytokine levels in patients with depressed left ventricular ejection fraction: a report from the Studies of Left Ventricular Dysfunction (SOLVD). J Am Coll Cardiol 1996;27:1201-6.

3 Ferrari R, Bachetti T, Confortini R, et al. Tumour necrosis factor soluble receptors in patients with various degrees of congestive heart failure. Circulation 1995;92:1479-86.

4 Deswal A, Petersen NJ, Feldman AM, et al. Cytokines and cytokine receptors in advanced heart failure: an analysis of the cytokine database from the Vesnarinone trial (VEST). Circulation 2001;103:2055-9.

5 Rauchhaus M, Doehner W, Francis DP, et al. Plasma cytokine parameters and mortality in patients with chronic heart failure. Circulation 2000;102:3060-7.

6 Yokoyama T, Vaca L, Rossen RD, et al. Cellular basis for the negative inotropic effects of tumour necrosis factor-alpha in the adult mammalian heart. $J$ Clin Invest 1993;92:2303-12.

7 Mandi Y, Hogye M, Talha EM, et al. Cytokine production and antibodies against heat shock protein 60 in cardiomyopathies of different origins. Pathobiology 2000;68:150-8.

8 Abdallah AN, Billes MA, Attia Y, et al. Evaluation of plasma levels of tumour necrosis factor alpha and interleukin-6 as rejection markers in a cohort of 142 heart-grafted patients followed by endomyocardial biopsy. Eur Heart $J$ 1997; 18:1024-9.

\title{
Effective treatment of a colchicine-resistant familial Mediterranean fever patient with anakinra
}

\section{Loes M Kuiik, Anita M A P Govers, Willem J D Hofhuis, Joost Frenkel}

$\mathrm{F}$ amilial Mediterranean fever (FMF) is an autoinflammatory disorder, characterized by periodic fever and serosal inflammation, often complicated by systemic amyloidosis.

Maintenance treatment of FMF with colchicine can reduce disease activity and prevent amyloidosis. Some patients, however, fail colchicine therapy. Many reports have recently

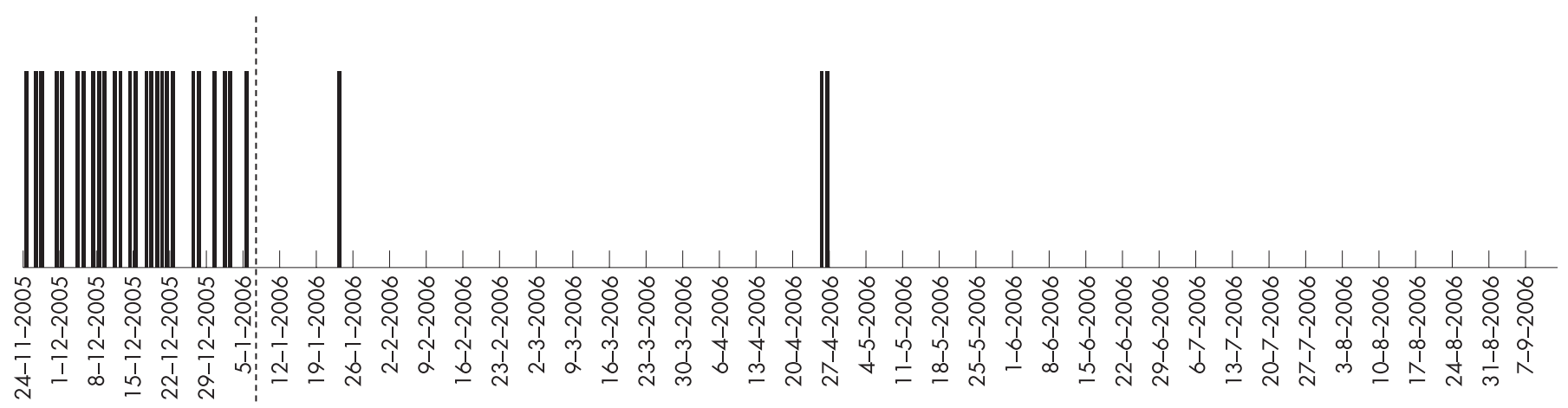

Figure 1 Disease activity before and during anakinra treatment. The bars indicate days when the patient reported being ill in her diary and/or her temperature exceeded $38^{\circ} \mathrm{C}$. The vertical dotted line indicates start of treatment. 
Table 1 Inflammatory mediators before and after initiation of anakinra therapy

\begin{tabular}{lllr}
\hline & Normal values* & Before & After \\
\hline C-reactive protein & $\leqslant 7.0$ & $44.4 \pm 9.9$ & $<7.0$ \\
IL- $1 \alpha$ (pg/ml) & $\leqslant 0.1$ & 223.9 & 60.6 \\
IL $\beta$ (pg/ml) & $\leqslant 1.3$ & 4.1 & 1.2 \\
IL-8 (pg/ml) & $\leqslant 0.3$ & 238.7 & 3.8
\end{tabular}

*Average values for age-matched healthy children (CRP) or healthy adults ( $\mathrm{n}=20$, cytokines).

been published concerning the effective use of a recombinant IL-1 receptor antagonist, anakinra, in several closely related disorders. ${ }^{1-4}$ These results prompted us to use anakinra in a 14year-old FMF patient who was unresponsive to colchicine therapy ( $2 \mathrm{mg} /$ day). A diagnosis of FMF was confirmed by analysis of the MEFV gene (pM694V, M694I).

The patient presented with febrile attacks accompanied by abdominal aches from the age of two years. With increasing age, the attacks became frequent (every 3-10 days), prolonged (12-88 hours) and more severe. The episodes consisted of an abruptly rising fever $\left(>40^{\circ} \mathrm{C}\right)$ accompanied by chills, anorexia, abdominal and retrosternal pain, arthralgias and also arthritis. In addition, the patient suffered from frequent bitemporal headaches and depression. Blood tests showed chronic microcytic anaemia and elevated inflammatory markers, which increased even more during attacks.

The patient was admitted to hospital and after confirmation of colchicine-resistant FMF, the patient and parents gave written informed consent for a trial of daily anakinra $100 \mathrm{mg}$ administered subcutaneously. Colchicine was initially maintained at $2 \mathrm{mg}$ a day.

After the initiation of anakinra treatment the fever did not recur (fig 1), nor did the patient experience abdominal pain or arthralgias even after gradually reducing the daily colchicine dose to $1 \mathrm{mg}$. The patient was less depressed and much more active. A transient mild urticarial rash on the hands and face was reported, which was well controlled with oral antihistamines. Laboratory results showed a remarkable improvement of the erythrocyte sedimentation rate and complete normalization of C-reactive protein. Furthermore, there was a reduction in serum IL- $1 \alpha$, IL- $1 \beta$ and IL- 8 levels, as measured by multiplex bead analysis ${ }^{5}$ (table 1). Surprisingly, all other cytokines measured (IL-2, IL-4, IL-5, IL-6, IL-10, IL-13, IL-18, IFN- $\gamma$ and TNF- $\alpha$ ) were either not elevated or did not change upon treatment with anakinra. Contrary to previous reports, ${ }^{2}$ we did not observe any changes in IL-6 levels after anakinra treatment.

Although favourable responses to anti-TNF- $\alpha$ agents have been described, ${ }^{6-8}$ this is the first report of a child with colchicine-resistant FMF successfully treated with anakinra. Similar results were reported in one adult FMF patient. ${ }^{9}$ Serious side effects of anakinra are rare. ${ }^{10}$ It therefore seems to be a safe agent for the treatment of auto-inflammatory disorders. Increased susceptibility to infections may, however, still pose a risk and patients obviously need to be monitored closely when anakinra treatment is initiated. We conclude that anti-IL-1 therapy in patients with colchicine-resistant FMF is potentially beneficial. Although none have been reported, treatment failures might occur in anti-TNF- $\alpha$ as well as in anti-IL-1 therapy. Therefore, a prospective trial comparing both therapies in FMF is warranted.

\section{Authors' affiliations}

Loes M Kuijk, Anita M A P Govers, Joost Frenkel, Departments of General Pediatrics and Pediatric Immunology, Division of Pediatrics, University Medical Center, Utrecht, the Netherlands

Willem J D Hofhuis, Department of Pediatrics, Catharina Hospital, Eindhoven, the Netherlands

Funding: L M K is supported by a grant from the Wilhelmina Children's Hospital Research Fund.

Correspondence to: Dr J Frenkel, Department of General Pediatrics, University Medical Center, Lundlaan 6, 3584EA Utrecht, the Netherlands; i.frenkel@umcutrecht.nl

Accepted 20 May 2007

\section{REFERENCES}

1 Dierselhuis MP, Frenkel J, Wulffraat NM, Boelens JJ. Anakinra for flares of pyogenic arthritis in PAPA syndrome. Rheumatology (Oxford) 2005;44:406-8.

2 Hoffman HM, Rosengren S, Boyle DL, et al. Prevention of cold-associated acute inflammation in familial cold autoinflammatory syndrome by interleukin-1 receptor antagonist. Lancet 2004;364:1779-85.

3 Hawkins PN, Lachmann HJ, McDermott MF. Interleukin-1-receptor antagonist in the Muckle-Wells syndrome. N Engl J Med 2003;348:2583-4.

4 Goldbach-Mansky R, Dailey NJ, Canna SW, et al. Neonatal-onset multisystem inflammatory disease responsive to interleukin-1 beta inhibition. N Engl J Med 2006;355:581-92.

5 de Jager W, Hoppenreijs EP, Wulffraat NM, et al. Blood and synovial fluid cytokine signatures in patients with juvenile idiopathic arthritis: a cross-sectional study. Ann Rheum Dis 2006:66:589-98.

6 Daysal S, Akcil G, Goker B, et al. Infliximab therapy in a patient with familial Mediterranean fever and chronic hip arthritis. Arthritis Rheum 2005;53:146-7

7 Ozgocmen S, Ozcakar L, Ardicoglu O, et al. Familial Mediterranean fever responds well to infliximab: single case experience. Clin Rheumatol 2006;25:83-7.

8 Mor A Pillinger $\mathrm{MH}$, Kishimoto $\mathrm{M}$, et al. Familial Mediterranean fever successfully treated with etanercept. J Clin Rheumatol 2007; 13:38-40.

9 Chae JJ, Wood G, Masters SL, et al. The B30.2 domain of pyrin, the familial Mediterranean fever protein, interacts directly with caspase-1 to modulate IL1\{beta\} production. Proc Natl Acad Sci U S A 2006; 103:9982-7.

10 Fleischmann RM, Tesser J, Schiff MH, et al. Safety of extended treatment with anakinra in patients with rheumatoid arthritis. Ann Rheum Dis 2006;65:1006-12. 